\title{
A revisão textual como forma de avaliação reflexiva e construção interativa entre professor e aluno
}

\author{
Textual review as a form of reflective evaluation and interactive \\ construction between teacher and student
}

\section{Revisión textual como una forma de evaluación reflexiva y construcción interactiva entre maestro y estudiante}

Jeize de Fátima Batista ${ }^{\prime}$

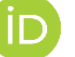

http://orcid.org/0000-0003-I30I-050X

Ana Cecilia Teixeira Gonçalves²

iD

http://orcid.org/0000-0002-5305-290X

Emanuele Krewer ${ }^{3}$

https://orcid.org/0000-0002-66|3-2853

Maiara Taís Zydek ${ }^{4}$

https://orcid.org/0000-0003-4233-7317

\begin{abstract}
Resumo: O presente trabalho trata da problemática da avaliação textual a partir da perspectiva textual-interativa (RUIZ, 200I). Após estudos teóricos sobre o assunto (FUZER, 2012; FUZER; WEBER, 20I2; MENEGASSI; GASPAROTTO, 2013, 2016), tem-se o objetivo de explicitar a importância e o significado que estratégias metodológicas, como bilhetes orientadores, apontamentos, questionamentos e comentários, possuem no melhoramento da produção escrita, uma vez que representam uma ferramenta dialógica utilizada entre professor e aluno com o intuito de revisar e de qualificar o texto. Por meio de exemplos que se baseiam nessa perspectiva de avaliação, evidencia-se a relevância da revisão textual a partir desse viés interativo. Como resultado da pesquisa, pode-se perceber que essas estratégias, por se basearem em uma concepção interativa de linguagem e
\end{abstract}

\footnotetext{
' Doutora em Letras. Professora de Língua Portuguesa e Linguística da Universidade Federal da Fronteira Sul (UFFS), Campus Cerro Largo, Rio Grande do Sul, Brasil. E-mail: jeize.batista@uffs.edu.br

${ }^{2}$ Doutora em Letras. Professora de Língua Portuguesa e Linguística da Universidade Federal da Fronteira Sul (UFFS), Campus Cerro Largo, Rio Grande do Sul, Brasil. E-mail: acgteixeira@uffs.edu.br

${ }^{3}$ Acadêmica do Curso de Letras da Universidade Federal da Fronteira Sul (UFFS), Campus Cerro Largo, Rio Grande do Sul, Brasil. E-mail: emanuelekrewericr@gmail.com

${ }^{4}$ Acadêmica do Curso de Letras da Universidade Federal da Fronteira Sul (UFFS), Campus Cerro Largo, Rio Grande do Sul, Brasil. E-mail: maiarazydek।@gmail.com
} 
em um entendimento processual de texto, possibilitam ao aluno entrar em contato com sua produção de um modo diverso da correção tradicional, o que as tornam metodologias de ensino diferenciadas.

Palavras-chave: Interação. Produção textual. Perspectiva de correção textual-interativa. Revisão textual.

\begin{abstract}
The present work deals with the problem of textual evaluation from the perspective textualinteractive (RUIZ, 200I). After theoretical studies on the subject (FUZER, 20I2; FUZER; WEBER, 20I2; MENEGASSI, GASPAROTTO, 2013, 2016), the objective is to explain the importance and meaning of methodological strategies, such as guidance notes, notes, questions and comments, have in improving written production, since they represent a dialogical tool used between teacher and student in order to review and qualify the text. Through examples that are based on this perspective of evaluation, the relevance of the textual review is evidenced from this interactive bias. As a result of the research, because they are based on an interactive conception of language and on a procedural understanding of the text, they allow the student to get in touch with their production in a different way from the traditional correction, which makes them differentiated teaching methodologies.
\end{abstract}

Keywords: Interaction. Text production. Perspective of textual-interactive correction. Textual revision.

Resumen: El presente trabajo aborda el problema de la evaluación textual desde la perspectiva de la corrección textual interactiva (RUIZ, 200I). Después de realizar estudios teóricos sobre el tema (FUZER, 20I2; FUZER; WEBER, 20I2; MENEGASSI, GASPAROTTO, 20I3, 20I6), se busca el objetivo de explicar la importancia y el significado que las estrategias metodológicas, tales como notas de orientación, apuntamientos, cuestionamientos y comentarios, tienen en el mejoramiento de la producción escrita, una vez que representan una herramienta de diálogo utilizada entre el profesor y el alumno para revisar y calificar el texto. A través de ejemplos que se basan en esta perspectiva de evaluación, la relevancia de la revisión textual se evidencia a partir de este modo interactivo. Como resultado de la investigación, se puede darse cuenta que esas estrategias al estar basadas en una concepción interactiva del lenguaje y una comprensión procedimental del texto, permiten a los estudiantes entrar en contacto con su producción de una manera distinta de la corrección tradicional, lo que las convierte en metodologías diferenciadas de enseñanza.

Palabras clave: Interacción. Producción de textos. Perspectiva de la corrección textual-interactiva. Revisión textual.

\title{
Introdução
}

Quando se trata de produção escrita, um dos primeiros princípios que se deve considerar é o fato de que um texto não é somente um produto final, mas, ao contrário, o resultado de um percurso de caráter processual (BUIN, 2006; FUZER; WEBER, 20I2; RUIZ, 200I). Por isso, no que diz respeito ao ensino da escrita, é preciso levar em conta o sujeito que escreve, o contexto que o circunda, o objetivo da produção, as estruturas textuais, e não somente questões ortográficas, aspecto esse que, por muito tempo, figurou como prioritário no processo de correção textual. Como apresenta Antunes (2003, p. 60):

Deve-se ter todo o cuidado para prestar atenção a outros aspectos do texto, para além da correção ortográfica. A tradição escolar tem conferido, por vezes, uma importância exagerada ao domínio da ortografia, criando a impressão de que basta a correção ortográfica para garantir a competência de escrever bons textos.

Geraldi (1984, p. 42), ao abordar a questão do ensino de Língua Portuguesa, ressalta que uma reflexão prévia é central: "para que ensinamos o que ensinamos? E sua correlata para que as 
crianças aprendem o que aprendem?5". Nesse sentido, conforme o autor, a resposta à questão deve estar fundamentada em uma concepção de linguagem; e é esse entendimento que vai nortear a atividade docente. $O$ autor aponta, pelo menos, três concepções de linguagem que estariam relacionadas a três correntes dos estudos da linguagem e, consequentemente, fazem-se presentes na sala de aula de Língua Portuguesa. A primeira estaria vinculada aos estudos tradicionais, à Gramática Tradicional, e entenderia a linguagem como "expressão do pensamento". A segunda, ligada ao estruturalismo, em especial, à teoria da comunicação, concebe a linguagem enquanto "instrumento de comunicação", enquanto "código". Por fim, o autor apresenta a concepção ligada à Linguística da Enunciação, a qual entende a linguagem enquanto "forma de interação" (GERALDI, 1984, p. 42). Nessa acepção, a linguagem é uma forma de agir socialmente.

Nesse ínterim, é possível observar aspectos históricos relacionados ao ensino de Língua Portuguesa, sobretudo no que diz respeito às diferentes concepções de linguagem e aos diferentes objetos de ensino que essa área apresentou ao longo dos tempos. Assim, o foco em tópicos ortográficos explicaria uma preocupação em levar para a sala de aula o conhecimento de uma variedade de língua correta, entendida sob o viés da homogeneidade, abordada por meio do estudo de regras que se pautam na Gramática Tradicional.

Tendo em vista as questões de escrita no âmbito do ensino de Língua Portuguesa, em especial a produção de textos pelo aluno e, por decorrência, a correção realizada pelo professor, observa-se que essas atividades também estão associadas à concepção de linguagem docente. Menegassi e Gasparotto (2013), ao tomarem como referência as proposições de Serafini (2004) e de Ruiz (200I), apresentam quatro concepções diferenciadas para a atividade de correção6: a) Correção indicativa, estratégia a partir da qual o professor apenas destaca o erro do aluno sem orientar a reescrita do texto; b) Correção resolutiva, estratégia por meio da qual o professor destaca o erro do aluno no texto e faz a correção; c) Correção classificatória, em que o professor destaca o erro e o classifica, a fim de que o aluno o resolva (por exemplo, ao identificar um erro de pontuação, o professor pode apontar a passagem e escrever "pontuação", chamando a atenção que há esse tipo de problema ali); d) Correção textual-interativa, na qual são utilizados bilhetes direcionados aos alunos com o objetivo de apontar erros, avanços e incentivar a reescrita, num contexto processual e interativo. Nota-se que as duas primeiras formas de entendimento da atividade de correção textual estariam ligadas a uma concepção tradicional de ensino; por outro lado, as duas últimas exigiriam do aluno uma atitude mais autônoma e

\footnotetext{
${ }^{5}$ Grifos do autor.

${ }^{6}$ Destaca-se que o termo “correção”, neste trabalho, é utilizado tendo como base os pressupostos de Menegassi e Gasparotto (2013).
} 
efetiva no que diz respeito à avaliação do próprio texto. Nesse âmbito, Geraldi (1984, p. 128) destaca que:

\begin{abstract}
Para mantermos uma coerência entre uma concepção de linguagem como interação e uma concepção de educação, esta nos conduz a uma mudança de atitude enquanto professores - ante o aluno. Dele precisamos nos tornar interlocutores para, respeitando-lhe a palavra, agirmos como reais parceiros: concordando, discordando, acrescentando, questionando, perguntando, etc. Note-se que, agora, a avaliação está se aproximando de outro sentido: aquele que apontamos em relação ao uso que efetivamente, fora da escola, se faz da modalidade escrita.
\end{abstract}

Desse modo, uma prática que considere o aspecto processual da escrita deve estar ancorada em uma concepção de linguagem enquanto ação social, espaço de interação. De acordo com Geraldi (1984), essa maneira de conceber a linguagem seria representativa de uma postura educacional diferenciada, em que os alunos seriam entendidos enquanto sujeitos, inseridos em um contexto de interação, de interlocução.

Assim, a atividade de revisão textual deve partir desta concepção de ir além da correção ortográfica, passando a entender a escrita enquanto processo, em que o professor, em vez de simples corretor, torna-se um interlocutor, orientando a qualificação do texto do aluno (FUZER, 2012). Isso não significa dizer que as questões ortográficas devem ser deixadas de lado, ao contrário, elas podem ser listadas, todavia a correção não deve se limitar a elas, isto é, também deve considerar outros aspectos relacionados ao texto (como os discursivos e os estruturais, por exemplo).

A perspectiva de correção textual-interativa, proposta por Ruiz (200l), tem essa especificidade: "a revisão docente tem caráter mediador, em que $\circ$ professor auxilia $\circ$ aluno, ampliando-lhe as possibilidades" (MENEGASSI, GASPAROTTO, 2016, p. 1020).

Sob esse viés interativo, o ensino da escrita precisa enfatizar as diferentes etapas da produção textual, a saber: planejamento (pré-escrita), escrita, revisão ou pós-escrita e reescrita. No entanto, em um contexto educacional, a grande dúvida está em "como" o professor pode intervir no texto de seu aluno sem adentrar na autonomia e bloquear a criatividade.

Em primeiro lugar, é necessário ter em vista que professor e aluno "jogam no mesmo time", e, por isso, a relação entre ambos deve ser de diálogo, o professor deve ajudar os alunos a superar suas dificuldades, encontrar seus erros e criar uma autonomia diante da escrita e da avaliação de seu texto. Ofugi e Figueredo (2017, p. 67) apontam:

A autonomia não é algo que simplesmente se "adquire" ou que se "tem", como pode ser entendido a partir da ideia de que um indivíduo pode "ter" ou "não ter" autonomia; ao contrário, trata-se de um processo pelo qual $\circ$ indivíduo vai aprendendo com o auxílio de outros. 
A partir dessa ideia, o professor precisa começar a pensar em como será a sua colaboração, como ele pode auxiliar o seu aluno de forma dialógica, contribuindo para o desenvolvimento da sua capacidade de escrita e também para o desenvolvimento de sua autonomia quanto às produções textuais. De acordo com Fuzer (20I2, p. 2I5): "mais do que apontar inadequações no uso do sistema linguístico em forma de textos, nosso compromisso como educadores da linguagem é encontrar maneiras eficientes de dialogar com os alunos via textos".

Dessa forma, com o intuito de auxiliar na problemática da revisão de textos em sala de aula, o presente artigo trata da perspectiva da correção textual-interativa e tem o objetivo de explicitar a importância e o significado que estratégias metodológicas, como os bilhetes orientadores (RUIZ, 200I, FUZER, 2012; FUZER; WEBER, 20 I2; BUIN, 2006), o apontamento, o questionamento e o comentário (MENEGASSI; GASPAROTTO, 2016) possuem no melhoramento da produção escrita, uma vez que representam uma ferramenta dialógica utilizada entre professor e aluno com o intuito de revisar e de qualificar o texto. Esse processo de revisão é um momento de troca, negociação e reflexão entre escritor e avaliador; a reescrita dos textos, por sua vez, será a resposta dada à revisão (MENEGASSI, GASPAROTTO, 2016).

Para dar conta disso, o trabalho divide-se em três momentos: em primeiro lugar, discorre-se sobre a proposta de correção textual-interativa, focalizando estratégias de revisão textual, como o bilhete orientador, o apontamento, o questionamento e o comentário; em seguida, apresentam-se procedimentos metodológicos que exemplificam a teoria apresentada; por fim, listam-se as considerações finais.

\section{A avaliação textual a partir da perspectiva textual-interativa}

A tarefa de avaliação textual não é fácil e implica em diversos aspectos, como a vinculação à concepção de linguagem que fundamenta a prática docente. Ao abordar o assunto, Fuzer (2012, p. 2I4) destaca:

Como acontece nas demais atividades pedagógicas envolvidas no ensino de língua, para conduzir o processo de produção textual, o professor geralmente adota um estilo interventivo em conformidade com sua concepção do que seja escrever e avaliar textos, o que, por sua vez, é reflexo da sua maneira de conceber a linguagem.

A partir desse mesmo viés, Menegassi e Gasparotto (2016, p. 1022) afirmam que "antes de iniciar a revisão de um determinado gênero textual produzido por uma turma, é imprescindível que o professor reflita sobre a finalidade e a metodologia desse processo". 
Sob esse enfoque, Fuzer $(2012)^{7}$ ressalta que o professor pode desempenhar diferentes posições diante do texto do aluno: leitor, assistente e avaliador. Segundo a autora, em uma posição de leitor, o professor reagirá às ideias do texto, ou seja, indicará se gostou ou não do que está escrito, mas sempre respeitando a produção do aluno. Quando o professor se coloca em posição de assistente, ele passa a auxiliar e a trabalhar com o autor do texto para a melhoria da produção escrita. Assim, em um processo interacional e dialógico, o texto é entendido como algo em construção. Por fim, exercendo o papel de avaliador, o professor faz comentários, por exemplo, sobre a atividade de linguagem do autor, sobre aspectos do texto que estão desenvolvidos adequadamente e sobre aspectos que ainda precisam ser ajustados. Aqui o foco deixa de ser o melhoramento do texto e passa a ser o desempenho futuro do autor.

É importante que o professor, em uma perspectiva textual-interativa, coloque-se em todas as posições descritas ao corrigir um texto, tendo claro que sua função não é somente apontar erros e fazer julgamentos da produção do aluno, mas, sim, agir como mediador, promovendo o desenvolvimento e o aperfeiçoamento das suas habilidades, fazendo com que ele se torne um escritor consciente, dono de palavras e que saiba utilizar essas palavras de maneira adequada. Em vista disso, a partir de uma abordagem que entende a escrita enquanto processo, "busca-se incentivar o desenvolvimento da autoria e propiciar o exercício da cidadania por meio da escrita" (FUZER; WEBER, 2012, p. 38)

Existem diferentes métodos que podem ser utilizados pelo professor para revisar e corrigir o texto do aluno. Neste trabalho, explorar-se-á a perspectiva de correção textual-interativa, proposta por Ruiz (200I), a qual tem como um dos instrumentos metodológicos utilizados para propiciar o desenvolvimento textual do aluno o bilhete orientador. Consoante a autora, por meio de bilhetes orientadores, o professor pode instigar o aluno a revisar seu texto, motivando-o a reescrevê-lo. Esse ponto será abordado a seguir.

\section{Bilhetes orientadores}

Fuzer (2012) salienta que os bilhetes orientadores consistem não só em elogiar o trabalho adequado de produção textual realizado pelo aluno, mas também em ajudá-lo a encontrar os seus erros e equívocos dentro do texto, fornecendo sugestões do que e como fazer. Assim, os bilhetes orientadores têm uma função de diálogo entre aluno e professor por meio do texto:

\footnotetext{
${ }^{7}$ Baseada em Tribble (1996). Ver mais informações em TRIBBLE, C. Writing. Oxford: OUP, 1996.
} 
Por meio de bilhetes orientadores, estabelece-se uma interlocução não codificada com o aluno, apontando-se problemas do texto e encaminhando-se soluções para a reescrita. Os comentários escritos ao aluno são mais longos do que os que se fazem na margem ou no corpo do texto (outros procedimentos que podem ser usados em combinação com o bilhete) (FUZER, 2012, p. 218).

Buin (2006, p. 122) ressalta que o bilhete orientador elaborado pelo professor, o qual é uma forma de correção textual-interativa, pode ser compreendido como um "instrumento auxiliador do desenvolvimento da escrita do aluno", isto é, representaria uma ferramenta crucial no processo de melhoramento de sua produção textual.

É interessante destacar que esse tipo de correção possibilita a criação de um processo interacional entre professor e aluno, em que o ensino e a aprendizagem se dão em um novo espaço, no qual o bilhete é usado com o objetivo de fazer com que o aprendiz reflita sobre seu texto e tente melhorá-lo. Conforme salienta Bazarim (2006, p. 61): "com esse tipo de estratégia, o professor espera que, através da interação mediada pelo bilhete, os alunos percebam e realizem as melhorias no texto que possam garantir ao leitor a construção do sentido".

Fuzer (2012) assinala marcas linguísticas utilizadas para verificar como a linguagem pode ser utilizada na interação entre professor e aluno, tanto no momento de provocação da escrita, quanto na orientação da reescrita. Essas marcas são apresentadas por meio dos bilhetes orientadores e categorizadas através de sistemas de "atitude e gradação" (FUZER, 20I2, p. 22I).

A atitude é quando o professor atribui ao texto do aluno afeto, julgamento e apreciação. No que diz respeito ao afeto, o professor se utiliza de elementos sentimentais como tristeza ou felicidade, satisfação ou insatisfação quanto à escrita do aluno. Já o julgamento pode ser entendido como "a maneira pela qual são avaliados os comportamentos em termos de normalidade, capacidade, tenacidade, propriedade e veracidade" (FUZER, 20I2, p. 22I). E, por último, a apreciação, refere-se à avaliação aos elementos do contexto (objetos, ações, eventos da vida, por exemplo).

Quando se fala de gradação, discorre-se sobre a intensidade das avaliações de afeto, julgamento e apreciação. Pode ser exemplificado como frases do tipo "lindo" "belo", "muitos", "poucos" e por advérbios de intensidade.

É importante dar uma atenção ao uso dessas categorias dos sistemas de atitude e gradação, pois elas influenciam muito na interação do bilhete orientador, e as palavras utilizadas podem fazer o aluno ter mais ou menos interesse pelo desenvolvimento da escrita. Por isso, é sempre importante não somente criticar os erros cometidos, mas também elogiar o que está correto e utilizar palavras adequadas de incentivo à escrita.

Fuzer (20I2) apresenta uma forma de construção de bilhetes orientadores que envolve todas essas esferas. Para isso, propõe quatro movimentos retóricos básicos para a elaboração do bilhete 
orientador, seriam estes: a) reações do leitor com relação ao texto do aluno; b) elogios à produção; c) orientações para a reescrita; e d) incentivo à reescrita.

O primeiro aspecto que deverá constar no bilhete orientador, como apresentado por Fuzer (2012), é a reação do leitor ao texto, ou seja, o professor escreverá o que achou do texto do aluno, em uma posição de leitor. Logo após, o professor fará elogios à produção, colocando em relevância os aspectos textuais que o aluno desenvolveu de forma adequada, com caráter motivacional, reconhecendo o trabalho do aluno. Vale ressaltar aqui que as estratégias interacionais utilizadas nos bilhetes, em especial "para iniciar e/ou manter o diálogo, bem como os recursos linguístico-discursivos utilizados" são de grande importância, pois podem desencadear "a construção de um novo papel interacional, o de interlocutor interessado" (BAZARIM, 2006, p. 64). Esse tom de interesse ajuda a construir um contexto de proximidade entre os interlocutores, fazendo com que a troca seja efetiva e funcional.

O terceiro ponto em que o professor deve focar é na orientação para a reescrita, uma das fases mais complexas, na qual o professor mostrará algumas falhas do texto do aluno, pode fazer um contraponto sobre os aspectos positivos e negativos do texto, da mesma forma que também pode fazer perguntas a fim de que o aluno busque e conserte o seu erro. É importante destacar somente alguns equívocos do aluno, não todos, uma vez que a revisão de muitos problemas pode sobrecarregálo e fazer com que não tenha motivação para a reescrita.

A última etapa desse processo é o incentivo a reescrita, em que o professor terá que deixar claro que os problemas do texto do aluno podem ser corrigidos, e, com isso, o seu texto ficará melhor e sua capacidade de produção mais desenvolvida. É importante nesse último aspecto utilizar métodos de conversação, pois aproximam ainda mais aluno e professor. Bazarim (2006, p. 42) relata a experiência pela qual passou através de bilhetes orientadores, e coloca:

A pouca formalidade se deve ao fato de [...] estabelecer um tipo de interação que aproximasse, professora e alunos, enquanto interlocutores. É por essa razão que é encontrado "Querida Suzana." e não "Prezada Aluna", "Beijocas" e não "Atenciosamente". É um estilo altamente interativo, no sentido de que pressupõe um envolvimento entre os interlocutores, o qual é marcado, sobretudo, nas expressões de abertura e encerramento.

Assim, pode-se perceber que os bilhetes orientadores são uma forma dinâmica, interativa e construtiva de realizar o melhoramento de textos. Essa técnica é muito indicada para crianças que estão no processo de aprendizagem de escrita e elaboração textual, assim como àquelas que estão no processo de qualificação da produção escrita, apesar de não se restringir apenas a essas classes. É um meio eficaz de tornar a relação entre professor e aluno mais afetiva, e, ao mesmo tempo, de ajudar a 
formar cidadãos leitores e mais críticos. Para dar continuidade, observam-se, abaixo, outras estratégias metodológicas baseadas na perspectiva textual-interativa de avaliação de textos.

\section{O questionamento, o apontamento e o comentário}

De acordo com Menegassi e Gasparotto (2016), as intervenções de revisão baseadas na perspectiva textual-interativa podem ser construídas de diversas maneiras, cada uma vinculada a aspectos específicos, como o objetivo do professor, o problema presente no texto, a idade escolar do aluno e as especificidades da pessoa que escreve o texto. Assim, tendo em vista que o bilhete orientador é considerado um gênero textual, conforme os autores, em decorrência da instabilidade dessa espécie de texto, o qual precisa estar adequado ao contexto imediato em que é elaborado, haveria uma variação dentro do próprio gênero. Desse modo, Menegassi e Gasparotto (2016) apontam outras estratégias metodológicas de correção baseadas na perspectiva textual-interativa, as quais podem ser entendidas como variações do bilhete orientador, a saber: o questionamento, o apontamento e o comentário. Ainda que essas estratégias de revisão possam ser consideradas bilhetes textuais, conforme proposta de Ruiz (200I), cada um apresenta "uma forma particular de construção, atendendo ao objetivo e a sua finalidade de produção" (MENEGASSI; GASPAROTTO, 20I6, p. I026).

O questionamento, o qual pode estar ligado a aspectos discursivos ou estruturais do texto, é usado quando o professor, por meio de perguntas, busca indagar os equívocos do aluno a fim de que ele - o aluno - entenda-os, e, no processo de reescrita do texto, possa corrigi-los. Seguem exemplos de questionamento: "E o título?"; “Como termina a história?"; "Que barulho é esse que João ouviu?" (MENEGASSI; GASPAROTTO, 2016, p. 1027).

Já o apontamento é um comentário simples, podendo ser uma frase cujo objetivo é informar o problema. Para esse tipo de trabalho, no entanto, é necessário um entrosamento entre professor e aluno, a fim de que o aluno entenda o apontamento do professor, pois, nesse tipo de estratégia, não há maiores orientações, ou seja, lista-se o problema e indica-se o que deve ser feito, sem explicações detalhadas. Seguem alguns exemplos desse tipo de intervenção: “Continue a história!”, “Atente para a pontuação!”, “Melhore o final de sua história!” (MENEGASSI; GASPAROTTO, 2016, p. 1030).

No que diz respeito ao comentário, é algo mais completo, uma intervenção detalhada que pode conter apontamentos, questionamentos e outras estratégias discursivas que tenham como finalidade a aproximação dos interlocutores. Por ser explicativo, o comentário permite ao professor escrever elogios aos aspectos adequados e positivos do texto, como também permite fazer levantamentos sobre os equívocos e, ainda, dar um incentivo ao aluno, para que, em seguida, realize a atividade de reescrita e a produção de futuros textos. Apresentam-se alguns exemplos dessa estratégia de revisão: “Ana, seu texto está confuso. A Maria Joaquina foi atrás dos bandidos? Por quê? Ela foi 
sequestrada?", "Carlos, preste atenção no seu texto, você escreveu algumas palavras erradas que deixaram o texto confuso. Acredito que você pode melhorar seu texto. Bom trabalho!", "Caique, conte mais sobre o que o menino e o vampiro fizeram no castelo dos monstros. Por que todos sumiram? Para onde foram? Estou curiosa para saber...” (MENEGASSI; GASPAROTTO, 2016, p. 1034).

Menegassi e Gasparetto (2016, p. 1039)8 apresentam componentes para a formulação de um comentário eficaz e que atenda à relação de interatividade entre aluno e professor: “I. Apresentação do problema; 2. Localização do problema na primeira versão do texto (correção indicativa); 3. Apresentação do contexto em que se encontra o problema (recursos de correção classificatória); 4. Diretrizes para a reformulação do problema".

Nesse sentido, os autores evidenciam que a correção textual-interativa pode ser realizada não só por meio de bilhetes orientadores, mas também por outras estratégias metodológicas diferenciadas, as quais também demonstram ter grande efetividade. A seguir, por meio de exemplos que se baseiam nessa perspectiva de avaliação, evidencia-se a relevância da revisão textual a partir desse viés interativo.

\section{Metodologia}

Consoante já apresentado acima, existem várias estratégias de avaliação textual baseadas em uma concepção de linguagem enquanto interação, como a elaboração de bilhetes orientadores, ou de apontamentos, questionamentos e comentários. Tendo em vista a apresentação e a discussão da perspectiva de correção textual-interativa, a partir de agora, analisa-se um texto de um aluno de $5^{\circ}$ ano, exemplificando-se alguns dos conceitos abordados, seus procedimentos de revisão e de correção. Destaca-se, nesse contexto, a relevância desses métodos para constituir um processo interativo entre professor e aluno durante as etapas da produção textual.

Antes de ler o texto, é interessante que se saibam informações sobre o contexto de produção e a situação de atividade de linguagem:

- Proposta de produção textual: depois de participar de várias oficinas sobre contos de detetive, pediu-se que estudantes do $5^{\circ}$ ano do Ensino Fundamental de uma escola pública do interior do Rio Grande do Sul escrevessem um texto pertencente ao gênero (GONÇALVES, 2008). Segue, abaixo, uma produção escolhida para a qual serão elaboradas ferramentas de revisão textual: bilhete orientador, apontamento, questionamento e comentário. O objetivo é mostrar como a teoria sobre a correção textual-interativa pode ser posta em prática, exemplificando para o professor que gostaria de trabalhar a partir dessa perspectiva.

\footnotetext{
${ }^{8}$ Baseados em Menegassi (2000). 
Quadro I - Produção textual: Conto de detetive

O sumiço do sol

Era uma vez um cientista maluco que tinha inventado uma maquina de emcolhimento e ele lançou seus raios contra o sol, era um raio muito forte que conseguia encolher o sol em meia hora só.

No outro dia não havia mais sol e todo o mundo ficou assustado. Ums perguntavam para os outros onde estava o sol, onde ele foi parar.

Ninguem sabia quem era o culpado por isso, chamaram no outro dia um detetive famoso por ter resolvido farios misterio mas ele disse que nunca avia visto um mistério que nem esse.

Foram procuralo imediatamente, tinha até em manchete "procura-ce um homem de barba grande com cabelo grande e escuro que é um cientista louco."

Até que uma noite nublosa uma mulher muito nervosa ligou para o detetive falando que vio o cientisto louco numa velha construção o detetive falou famos emediatamente para lá, foram entam para lá e acharam enle dentro de um quarto trancado o detetive teve que aronbar a porta e prenderam ele. No outro dia estavam julgando ele que vai condenado a prição perpetua. Mas o detetive não sabia como fazer o sol voltar até que um homem encontrou um liquido verde e pegaram o liquido colocaram na maquina de encolher trocaram a potência e lançaram para o céu e o sol voltou em 2 dias

Aluno $\mathrm{X}, \mathrm{II}$ anos

Fonte: Gonçalves (2007).

A partir dessa produção, abaixo, são apresentadas propostas de correção textual-interativa, de acordo com o referencial teórico apresentado. Para dar conta do objetivo, partes do texto serão reproduzidas para exemplificar as orientações, além disso, a fim de facilitar a compreensão do leitor, os equívocos do autor do texto serão sublinhados e as sugestões do professor serão grifadas com caixa alta.

\section{Correção textual-interativa: questionamento}

Como se observou a partir das discussões teóricas apresentadas, por meio da estratégia do questionamento, o professor tenta evidenciar problemas encontrados no texto do aluno através de perguntas, como explicita o Quadro 2.

Quadro 2 - Exemplificação da estratégia de correção questionamento

No outro dia não havia mais sol e todo o mundo ficou assustado. Ums (SERÁ QUE ESTA PALAVRA ESTÁ
ESCRITA CORRETAMENTE?) perguntavam para os outros onde estava o sol, onde ele foi parar.
Ninguem (QUE TAL REVISARMOS A ACENTUAÇÃO?) sabia quem era o culpado por isso, chamaram no
outro dia um detetive famoso por ter resolvido farios (NÂO SERIA “VÁRIOS"?) mistério mas ele disse que
nunca avia (POR QUE NO PARÁGRAFO ACIMA VOCÊ ESCREVEU "HAVIA"E AGORA ESCREVEU "AVIA"?
VOCÊ PODE UTILIZAR UM DICIONÁRIO PARA TIRAR DÚVIDAS DE GRAFIA E SIGNIFICADOS, SE
NECESSÁRIO) visto U Um mistério que nem esSe (QUE TAL UTILIZAR OUTRA PALAVRINHA OU
EXPRESSÃO - MAIS DE UMA PALAVRA - QUE DÊ IDEIA DE COMPARAÇÃO?).

Fonte: Elaborado pelas autoras, 2020. 
Nota-se que o professor identifica problemas no texto e os questiona, com o intuito de que $\circ$ aluno entenda o que é colocado e resolva as inadequações linguístico-gramaticais, bem como textuais. Assim, no exemplo dado, podem-se identificar questionamentos acerca de problemas mais pontuais, como grafia de palavras e acentuação (SERÁ QUE ESTA PALAVRA ESTÁ ESCRITA CORRETAMENTE?; QUE TAL REVISARMOS A ACENTUAÇÃO?), bem como sobre uso de conectores e sobre sua função no texto (QUE TAL UTILIZAR OUTRA PALAVRINHA OU EXPRESSÃO - MAIS DE UMA PALAVRA - QUE DÊ IDEIA DE COMPARAÇÃO?).

\section{Correção textual-interativa: apontamento}

Com o uso de apontamentos, o objetivo é intervir brevemente e de modo um tanto objetivo. Para isso, costuma-se usar verbos no imperativo e assertivas que contêm indicação do que deve ser feito pelo aluno, como se pode observar no Quadro 3.

Quadro 3 - Exemplificação da estratégia de correção apontamento

No outro dia não havia mais sol e todo o mundo ficou assustado. Ums (CUIDADO COM A ESCRITA DA PALAVRA!) perguntavam para os outros onde estava o sol, onde ele foi parar.

Ninguem (ATENÇÃO NO USO DA ACENTUAÇÃO!) sabia quem era o culpado por isso, chamaram no outro dia um detetive famoso por ter resolvido farios mistério (CUIDE A ESCRITA DA PRIMEIRA PALAVRA...PENSE COMO VOCÊ A PRONUNCIA; ALÉM DISSO, NOTE QUE A PRIMEIRA PALAVRA ESTÁ NO PLURAL, PORTANTO, A SEGUNDA TAMBÉM DEVE ESTAR.) mas ele disse que nunca avia (VERBO HAVER: ATENÇÃO AO ESCREVER!) visto um mistério que nem esse.

Fonte: Elaborado pelas autoras, 2020.

Nos apontamentos, é possível notar intervenções indicativas que listam problemas de grafia, de acentuação e de concordância. Observa-se que o uso do imperativo (CUIDE, PENSE, NOTE) e de assertivas (CUIDADO COM A ESCRITA DA PALAVRA!, ATENÇÃO NO USO DA ACENTUAÇÃO!) indicam, de maneira objetiva, o que deve ser revisado pelo aluno.

\section{Correção textual-interativa: comentário}

A partir da elaboração de comentários, o professor trata de aspectos discursivos, estruturais ou ortográficos. Destaca-se que essa ferramenta pode trazer apontamentos e questionamentos, configurando-se como uma forma mais completa de revisão, conforme Quadro 4. No texto, marcamse passagens com negrito, itálico e sublinhado. 
Quadro 4 - Exemplificação da estratégia de correção comentário

Seu texto está muito bom! É uma autêntica história de detetive! Parabéns! Está criativo e não há problemas quanto ao seu entendimento, mas é preciso que você dê uma atenção especial à escrita das palavras (ortografia), à acentuação e ao uso do plural. Observe as palavras, a seguir, elas precisam de revisão: "Ums, farios, Ninguem, avia". Lembre-se do que falávamos sobre o uso do verbo haver? Em seu texto, você escreveu "havia" "avia". Dê uma olhada! Sugiro que leia seu texto novamente e faça esses pequenos ajustes necessários para que ele fique ainda melhor. Bom trabalho!

Fonte: Elaborado pelas autoras, 2020.

No comentário elaborado, observa-se a tentativa de interação, a partir da constituição de um espaço dialógico, em que se debate sobre o texto produzido, dão-se sugestões e se motiva o aluno. Identificam-se, também, componentes básicos propostos por Menegassi e Gasparotto (2016): a apresentação do problema (MAS É PRECISO QUE VOCÊ DÊ UMA ATENÇÃO ESPECIAL À ESCRITA DAS PALAVRAS, À ACENTUAÇÃO E AO USO DO PLURAL); a apresentação do contexto em que se encontra o problema (OBSERVE AS PALAVRAS, A SEGUIR, ELAS PRECISAM DE REVISÃO: “UMS, FARIOS, NINGUEM, AVIA”.) e as diretrizes para reformulação do problema (LEMBRE-SE DO QUE FALÁVAMOS SOBRE O USO DO VERBO HAVER?; SUGIRO QUE LEIA SEU TEXTO NOVAMENTE E FAÇA ESSES PEQUENOS AJUSTES NECESSÁRIOS PARA QUE ELE FIQUE AINDA MELHOR.). Na continuidade, apresenta-se um exemplo de escrita de bilhete orientador.

\section{Bilhete orientador}

Parte-se, agora, para a exemplificação de aspectos que constituem o bilhete orientador. Nesse sentido, segue-se um modelo de bilhete feito com base nos passos indicados por Fuzer (2012) e por Fuzer e Weber (2012), já citados neste artigo. Para uma melhor compreensão, os movimentos retóricos básicos do bilhete foram marcados entre parênteses com caixa alta e as passagens de escrita do aluno foram colocadas entre parênteses, em itálico e sublinhadas; ainda, marcou-se pontualmente a inadequação com negrito.

Quadro 5 - Exemplificação da estratégia de correção bilhete orientador

Adorei ler seu texto! Eu me senti como se fizesse parte da história, com todo o suspense em descobrir onde se escondeu o cientista e pensando que nenhum detetive era bom o bastante para encontrá-lo. ( $\underline{R E A C \tilde{A} O}$ DO LEITOR)

Seu texto está muito bem organizado e é de fácil compreensão. Você descreveu bem os fatos, pessoas e espaço e me pareceu muito interessante a forma como trouxe os detalhes, como, por exemplo, quando disse que a busca pelo cientista maluco estava até em manchetes. (ELOGIOS À PRODUCÃ̃O)

Agora, para que seu texto fique ainda melhor, que tal darmos uma atenção especial a algumas partes em que existem pequenas inadequações que você cometeu? Leia seu texto e preste atenção em como você utilizou a letra " $f$ " no lugar do " $v$ ", como, por exemplo, nas palavras "vamos" e "vários" (chamaram no outro dia um detetive famoso por ter resolvido farios misterio, linhas 6-7; o detetive falou famos emediatamente para lá). 
Também dê uma atenção especial ao verbo "Haver". Observe que sua escrita é com " $h$ " e, em seu texto, aparecem duas formas diferentes de escrita desse verbo: (No outro dia não havia mais sol e todo o mundo ficou assustado, linha 4; nunca avia visto um mistério que nem esse). Além disso, veja outras palavrinhas que possam estar incorretas, sem esquecer que o uso da pontuação e acentuação sempre requerem um cuidado especial, não é mesmo?

Outra sugestão é que dê uma olhada no seu último parágrafo. Quando termina a história, diz que o cientista foi encontrado em uma velha construção em um quarto fechado. Essa construção estava acabada? Já havia cômodos prontos? Fiquei um pouco confusa... (ORIENTAÇ̃̃O PARA REESCRITA)

Assim que você concluir os pequenos ajustes em seu texto, ele ficará ainda melhor! Que tal começarmos logo? (INCENTIVO À REESCRITA).

Fonte: Elaborado pelas autoras, 2020.

É possível perceber que o bilhete apresenta os quatro movimentos básicos listados por Fuzer (20I2) e por Fuzer e Weber (20I2): primeiramente, há um momento de reação do professor, o qual salienta sua satisfação ao ler o texto; logo, são feitos elogios à escrita do aluno, com o intuito de motivar sua reescrita e suas futuras produções. Depois, são listadas algumas passagens que precisam ser revisadas e são dadas orientações para que o aluno faça essa reflexão. Por fim, incentiva-se a reescrita, destacando-se o processo de melhoramento do texto.

Categorias linguísticas também são utilizadas para construir uma situação de atitude e de gradação (FUZER, 20I2). Na passagem, “ADOREI LER SEU TEXTO! EU ME SENTI COMO SE FIZESSE PARTE DA HISTÓRIA", pode-se notar o registro de sentimento positivo por parte do professor. Além disso, identificam-se passagens de julgamento, em que se avalia o comportamento linguístico do autor: "SEU TEXTO ESTÁ MUITO BEM ORGANIZADO E É DE FÁCIL COMPREENSÃO; QUANDO TERMINA A HISTÓRIA DIZ QUE O CIENTISTA FOI ENCONTRADO EM UMA VELHA CONSTRUÇÃO EM UM QUARTO FECHADO. ESSA CONSTRUÇÃO ESTAVA ACABADA? JÁ HAVIA CÔMODOS PRONTOS? FIQUEI UM POUCO CONFUSA...". Marcas de apreciação, em que são avaliados elementos do ambiente, também podem ser observadas: "VOCÊ DESCREVEU BEM OS FATOS, PESSOAS E ESPAÇO E ME PARECEU MUITO INTERESSANTE A FORMA COMO TROUXE OS DETALHES, COMO, POR EXEMPLO, QUANDO DISSE QUE A BUSCA PELO CIENTISTA MALUCO ESTAVA ATÉ EM MANCHETES".

Para dar mais informações, o quadro abaixo (Quadro 6) apresenta um exemplo de bilhete que foque nas categorias de atitude.

\section{Quadro 6 - Atitude}

Uau! Estou impressionada com a sua criatividade ( $\underline{\text { AFETO }})$. Também achei muito bacana como você trouxe a busca pelo cientista em manchetes para o seu texto ( $\underline{A P R E C I A C C A ̃ O})$. Só não compreendi muito bem a parte em que você disse que o homem estava em uma velha construção e foi encontrado em um quarto trancado. Essa velha construção tinha um quarto trancado? Era uma construção já terminada? Fiquei um pouco confusa... (JULGAMENTO)

Fonte: Elaborado pelas autoras, 2020.

Ademais, categorias de gradação aparecem no bilhete elaborado pelo professor. Nota-se a utilização de advérbios intensificadores que conferem força ao que é colocado, ainda, advérbios de 
modo, marcadores avaliativos, subjetivos: "SEU TEXTO ESTÁ MUITO BEM ORGANIZADO E É DE FÁCIL COMPREENSÃO. VOCÊ DESCREVEU BEM OS FATOS, PESSOAS E ESPAÇO E ME PARECEU MUITO INTERESSANTE A FORMA COMO TROUXE OS DETALHES". Também, traz o uso de quantitativos indefinidos: "PENSANDO QUE NENHUM DETETIVE ERA BOM O BASTANTE PARA ENCONTRÁ-LO”.

A seguir, o Quadro 7 apresenta um bilhete em que há destaque para a categoria linguística de gradação.

\section{Quadro 7 - Gradação}

Você é muito criativa!

A organização de seu texto está ótima!

Você utilizou pouco os sinais de pontuação, tome cuidado com isso!

Fonte: Elaborado pelas autoras, 2020.

Para Fuzer (20I2), tais categorias linguísticas auxiliam na construção do bilhete orientador, salientado a atitude do enunciador, o qual pode demonstrar diferentes sentimentos perante o texto do aluno. Contribuem, ainda, para criar um espaço de interação e proximidade, no intuito de tornar a revisão um processo de qualificação do texto. Assim, tanto o bilhete como as demais ferramentas de revisão (apontamento, questionamento e comentário), apresentam-se como excelentes estratégias de correção textual, uma vez que possibilitam constituir um meio de interlocução entre professor e aluno.

\section{Considerações finais}

A correção de uma produção escrita vai muito além da estrita indicação de erros ortográficos, abrangendo, assim, questões contextuais, ligadas à situação de produção, e textual-discursivas. Em vista disso, tendo claro que o papel do professor no momento da correção textual é de leitor, assistente e avaliador, buscou-se trazer metodologias que aproximem o professor do autor do texto de modo interativo e dialogado, sem excluir a autonomia e a criatividade do aluno.

Dessa forma, partiu-se de uma perspectiva de correção textual interativa, por meio de bilhetes orientadores e de outras estratégias metodológicas, que se apresentam segundo um viés de reflexão e de melhoramento do texto. Assim, o professor passa a fazer observações com relação à produção do aluno e, além disso, indica o que e como melhorar no texto.

Dentro desta perspectiva, são apresentados vários artifícios para a correção do texto, como, por exemplo, construção de bilhetes com movimentos retóricos específicos, utilização de categorias linguístico-gramaticais e textuais, questionamentos, apontamentos, comentários etc. Essas estratégias ajudam a compreender como o professor pode, ao mesmo tempo, avaliar e instruir a revisão do aluno, 
sem fazer com que ele perca o interesse para a reescrita de seu texto. Independentemente da estratégia metodológica, seja a partir de bilhete orientador, de questionamento, de apontamento ou de comentário, o mais importante é que a avaliação a respeito do texto do aluno seja reflexiva, dialógica e interativa.

Sob esse viés, apresentaram-se exemplos de correções textuais que se fundamentam nessa perspectiva interativa, de diálogo e de reflexão. Com isso, ao mostrar possibilidades de construção de um bilhete orientador ou de outras estratégias de interlocução, objetivou-se auxiliar o professor no processo de avaliação dos textos dos alunos por meio da perspectiva de correção textual-interativa.

Nesse sentido, entende-se que as ferramentas apresentadas podem promover interação e aproximação entre professor, aluno e texto. Além de possibilitar que o autor reflita sobre o que escreveu, não somente sobre seus erros ortográficos, mas sobre toda a produção, é a partir das orientações e incentivos apresentados que o aluno, por meio do diálogo com a avaliação, poderá melhorar o seu texto. Esse contato com a produção realizada, a partir de um viés interativo de linguagem, dá-se de um modo diverso da correção tradicional, o que torna essa metodologia de ensino diferenciada.

\section{Referências}

ANTUNES, I. Aula de português: encontro e interação. São Paulo: Parábola Editorial, 2003.

BAZARIM, M. Construindo com a escrita interações improváveis entre professora e alunos do ensino fundamental de uma escola pública da periferia de Campinas/Milene Bazarim. Campinas, SP: [s.n.], 2006.

BUIN, E. O impacto do bilhete do professor na construção do sentido do texto do aluno. In:

SIGNORINI, I. (Org.). Gêneros catalisadores: letramento e formação do professor. São Paulo: Parábola, 2006.

FUZER, C. Bilhete orientador como instrumento de interação no processo de aprendizagem de produção textual. Letras, Santa Maria, v. 22, n. 44, p. 213-245, jan./jun. 2012.

FUZER. C.; WEBER, T. Um passo de cada vez. A (re)escrita em resposta a feedbacks no processo ensino-aprendizagem de produção textual. Cadernos de Linguagem e Sociedade, Brasília, v. I3, n. 2, p. 36-60, nov. 2012.

GERALDI, J. W. (Org.). O texto na sala de aula: leitura e produção. 2. ed. Cascavel: Assoeste, 1984.

GONÇALVES, A. C. T. A escrita no contexto escolar: relação entre concepção e

desenvolvimento. 2007. Dissertação (Mestrado em Letras) - Universidade Federal de Santa Maria, Santa Maria, 2007. 
MENEGASSI. R. J.; GASPAROTTO. A mediação do professor na revisão e reescrita de textos de aluno de Ensino Médio. Calidoscópio, Unisinos, v. II, n. I, jan./abr. 2013.

MENEGASSI. R. J. Comentários de revisão na reescrita de textos: componentes básicos. Trabalhos em Linguística Aplicada, Campinas: n35, p. 84-93, 2000.

MENEGASSI. R. J.; GASPAROTTO. D. M. Revisão textual-interativa: aspectos teórico-metodológicos. Domínios da Lingu@gem, Uberlândia, v. 10, n. 3, jul./set. 2016.

OFUGI, M. S.; FIGUEREDO, C. J. Desenvolvendo a autonomia do aprendiz de inglês como L2/LE com o auxílio da técnica da sala de aula invertida: um estudo de caso. Linguagem \& Ensino, Pelotas, v. 20, n. 2, p. 55-80, jul./dez. 2017.

RUIZ, E. Como se corrige redação na escola. Campinas, SP: Mercado de Letras, 200 I.

SERAFINI, M. T. Como escrever textos. Trad. Maria Augusta de Matos; Adap. Ana Maria Marcondes Garcia. I2. ed., São Paulo, Globo, 2004.

TRIBBLE, C. Writing. Oxford: OUP, 1996.

Recebido em: 29 de junho de 2020.

Versão corrigida recebida em: 15 de novembro de 2020.

Aceito em: 01 de junho de 202I.

Publicado online em: 04 de fevereiro de 2022. 